Ind. Health, 1971, 9, 59.

\title{
INFRARED SPECTROMETRIC AND GAS CHROMATOGRAPHIC IDENTIFICATIONS OF ORGANIC SOLVENTS IN COMMERCIAL MATERIALS USED IN INDUSTRY FOR ESTIMATION OF TOXIC SUBSTANCES
}

\author{
Reisuke SODA \\ National Institute of Industrial Health Kizuki Sumiyoshi, Kawasaki
}

(Received March 13, 1971)

\begin{abstract}
Identification of composition of organic solvents is very important for evaluation of industrial environment. Gas chromatographic and infrared spectrometric analyses are suitable to identify organic solvents in commercial materials. The volatile components in the solvents have been identified by gas chromatography. The identification is certified by infrared spectrometric analysis of gas chromatographic eluates. In some cases analysis by only gas chromatograph gives an erroneous result and it is generally desirable to identify each component eluted from chromatographic column by infrared spectrometry. These examples are illustrated by using commercial materials including several solvents. ATR method also is useful to infer the possible kinds of solvents used from the knowledge on non volatile substances in the materials.
\end{abstract}

Industrial poisoning is caused by contaminants in ambient air of working place, one of which is organic solvent. Any organic solvent used in practice has vapor pressure at normal temperature and evaporates into the air, increasing concentration of vapor in industrial environment. For the health of workers in working place it is necessary to analyze toxic substances in the ambient air. For this purpose an analysis of the components of the materials used in the place is very useful for the analysis of vapor in the air, as the information on the components of materials used makes easier a selection of analytical methods. Furthermore it may, in some cases, give the knowledge on the possible cause of industrial poisoning prior to analysis of vapor in the air. The amounts of organic solvents in commercial materials are generally sufficient for analysis of organic solvents in the materials compared with those collected for analysis of vapor in ambient air and the former analysis is relatively not so troublesome that usual analytical method can be applied without any special treatment like particular sampling. Gas chromatography and infrared spectrometry are preferable for above stated purpose.

Information on non volatile substances in the commercial materials may make inference of organic solvent used and attenuated total reflectance (ATR) technique is very suitable for the analysis of non volatile substance, as ATR is useful for 


\section{R. SODA}

determination of resin and pigments which can not be analyzed by usual transmission spectrometry. ${ }^{1)}$

\section{EXPERIMENTALS}

\section{Materials}

Pure organic solvents were used to observe standard spectra and standard gas chromatograms. The solvents were special grade or chemically pure reagents and used without any purification. Impurities were found gas chromatographically less than $0.01 \%$. Some adhesives and adhesive solvents or dye solvents used to test the present method.

\section{Infrared spectrum}

Infrared spectrometer used was Hitachi EPI G 2, resolution of which was $1 \mathrm{~cm}^{-1}$ at $1000 \mathrm{~cm}^{-1}$ in normal condition for operation. Wave number of spectrum was calibrated by polystyrene film. Vapor spectrum was obtained by a gas cell equipped with KRS-5 windows on both sides and made by glass cylinder of $10 \mathrm{~cm}$. Two glass tubes with cocks were connected to a horizontal side of the cell. The gas cell was inserted in sample area of spectrometer and an optical screen was used to adjust $100 \%$ position of recorder pen by attenuating partly reference beam.

A spectrum of non volatile substance was obtained with attenuated total reflectance equipment (Hitachi ATR-1). It consisted of KRS-5 prism and optical alignment system. The optical screen was inserted in reference area. Sample was usually pressed on one side of prism surface, by which twice internal reflection was obtained. Sample which showed weak absorption spectrum was pushed on both sides of prism and three times reflection was obtained.

\section{Gas chromatography}

Two types of gas chromatographs were employed for identification of volatile components. Main experiment was performed by Ohkura gas chromatograph Model 6000 equipped with thermal conductivity detector. Carrier gas was helium. Column was made by stainless steel of $6 \mathrm{~mm}$ in outer diameter. Packed material was Porapak $\mathrm{Q}$ or $\mathrm{P}$ (50 to $80 \mathrm{mesh}$ ). Temperature in column oven was controlled at $130^{\circ}$ to $180^{\circ} \mathrm{C}$ and that in detector was $190^{\circ} \mathrm{C}$. Sample size was $10 \mu \mathrm{l}$ or $1 \mu \mathrm{l}$ for liquid and $1 \mathrm{ml}$ for gaseous sample. Some identifications of minor components was carried out by Perkin Elmer Model 800 vapor Fractometer equipped with flame ionization detector.

\section{Experimental procedure}

Sample was put in the wide bottom dish like a petri dish and it was gently warmed to evaporate volatile component. If sample did not contain any non volatile substances, that is sample was only solvents volatile, no substance remainded in the dish. In this case sample was directly injected into the gas chromatograph by a microsyringe. First, chromatogram was observed in relatively low temperature 


\section{IDENTIFICATIONS OF ORGANIC SOLVENTS}

to identify peaks of the component which has low boiling point or short retention time with Porapak column. Then temperature was raised and chromatogram of the same sample was again observed, to analyze the components eluted very slowly. The standard pure solvent was injected into the gas chromatograph at the same temperature as operated for the sample. The infered solvent of $1 \mu \mathrm{l}$ or less mixed in the sample of $10 \mu \mathrm{l}$ and chromatogram of the mixture was again observed to certify the component identification. The major peak component eluted from chromatograph was introduced into gas cell and the vapor infrared spectrum was observed for confirmation.

If sample contained non volatile component, the sample was put in a petri dish which was inserted in the flask of large volume with two side tubes as shown in Fig. 1. Air was circulated by a pump through gas sampler of gas chromatograph. The circulation flow rate was about $11 / \mathrm{min}$. After circulation of $10 \mathrm{~min}$, the sample was injected into the gas chromatograph. Similar apparatus was used to introduce the volatile components in the material into the gas cell for infrared spectrometic analysis. Column temperature was in higher range to complete chromatogram quickly. Two or more chromatograms were scanned to certify that the circulation was sufficient to establish vapor liquid equilibrium in the flask. Then in suitable temperature sample chromatogram was observed. Those chromatograms were observed with Ohkura gas chromatograph. The major component was also collected in the gas cell to observe the infrared spectrum.

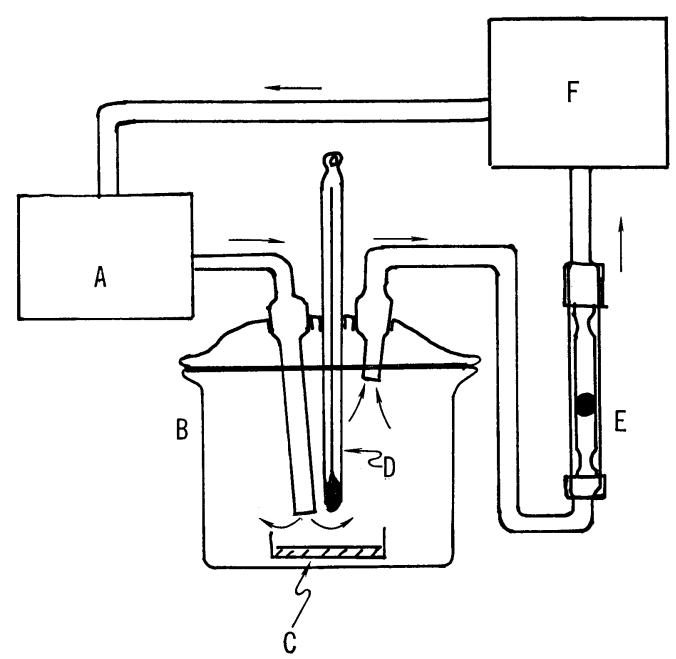

Fig. 1. Schematic diagram for preparing vapor liquid equilibrium in flask to drive vapor into gas sampler of gas chromatograph. Arrow line is direction of air flow. A, Diaphragm pump; B, Separable flask; C, Vessel for sample; D, Thermometer; E, Float type flow meter; F, Gas sampler of gas chromatograph. 


\section{R. SODA}

Non volatile substance was identified by infrared spectrum with ATR. Sample liquid was placed widely and flat as possible on the flat glassplate or plastic sheet which did not react with the solvent or adhesive. The plate or sheet was gently heated at 60 or $70^{\circ} \mathrm{C}$ on the hot plate to evaporate volatile component. Resulted thin film was pushed on the reflection surface of ATR prism as shown in Fig. 2. If film did not remove from glass plate or plastic sheet, the resulted film was pushed tightly together with the plate or sheet. ATR spectrum was obtained with the sample put tightly on the prism surface by pushing them by rubber plate. Loose attached film gave poor spectrum caused by air between both surfaces of prism and film. Evaporation was accelerated by blowing air on the surface of film. This technique gave sometimes an accumulation of film layer in one side against blowing side. Therefore wind blowing should be carefully done and not be strong. Infrared spectrum was compared with standard spectrum or known spectrum and determination was confirmed by the coincidence of both sepctra.
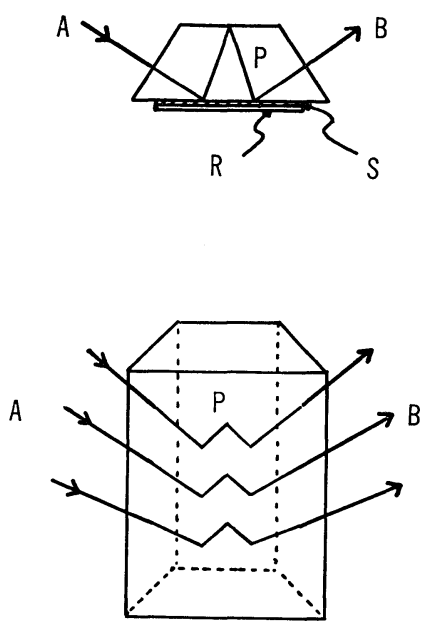

Fig. 2. Schematic diagram of prism of attenuated total reflectance (ATR).

Light passes from A to B.

P, KRS-5 prism; S, Sample film of non volatile substance; $R$, Rubber plate for pushing film.

\section{RESULTS}

A sample solvent which was used to bind resin each other, remainded non volatile substance on the glass plate when liquid was spread on the plate and evaporated by heating gently. Infrared spectrum with ATR of this polymer film showed polymer of methyl methacrylate as shown in Fig. 3. Infrared spectrum of carbon tetrachloride solution of the sample showed bands of several components as shown in Fig. 3. The polymer was considered to be formed the evaporation of liquid heating gently. If the evaporation was carried out in lower temperature 


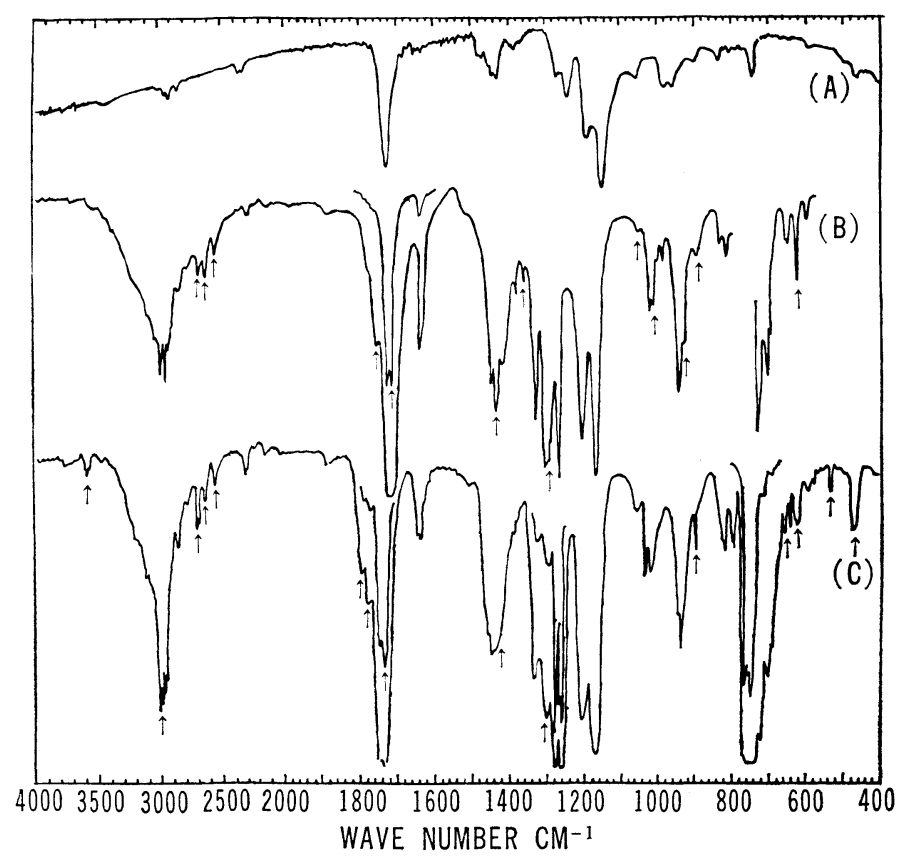

Fig. 3. Infrared spectrum of commercial material.

(A) Non volatile film formed by evaporation of solvent on flat teflon sheet. (B) Carbon tetrachloride solution of sample liquid. (C) Vapor of sample liquid in gas cell. Bands indicated by arrows are due to acetic acid.

like a room temperature, the polymer was produced so little that infrared spectrum of a remainded film was very weak and sometimes no bands were observed. The sample was directly injected into gas chromatograph with microsyringe. Fig. 4 shows the chromatogram of this sample. The vapor sample also was injected into gas chromatograph by using apparatus illustrated schematically in Fig. 1, and gave similar (approximately the same) chromatogram as liquid sample as shown in Fig. 5. The main peaks were two and the infrared spectra of those eluted components were the same as spectrum of methylene dichloride and that of methyl methacrylate as shown in Fig. 6. The vapor spectrum of liquid showed acetic acid bands as indicated by arrow lines on the spectrum shown in Fig. 3. By above analysis, the sample component was identified as three compounds; methylene dichloride, methyl methacrylate and acetic acid.

Fig. 7 shows infrared spectra of non volatile substances in some adhesive and enamel by ATR. Sample was spread on the teflon sheet to evaporate solvent gently. The teflon sheet $2 \mathrm{~mm}$ in thickness was found to best for present experiment. Rapid evaporation caused curring or contracting of formed film and made measurement of spectrum difficult. Resulted sheet was pushed on prism of ATR and infrared spectrum was observed. Spectrum B in Fig. 7 was obtained by enamel and revealed that the sample contained polar functional group (at $3300 \mathrm{~cm}^{-1}$ ), mainly 


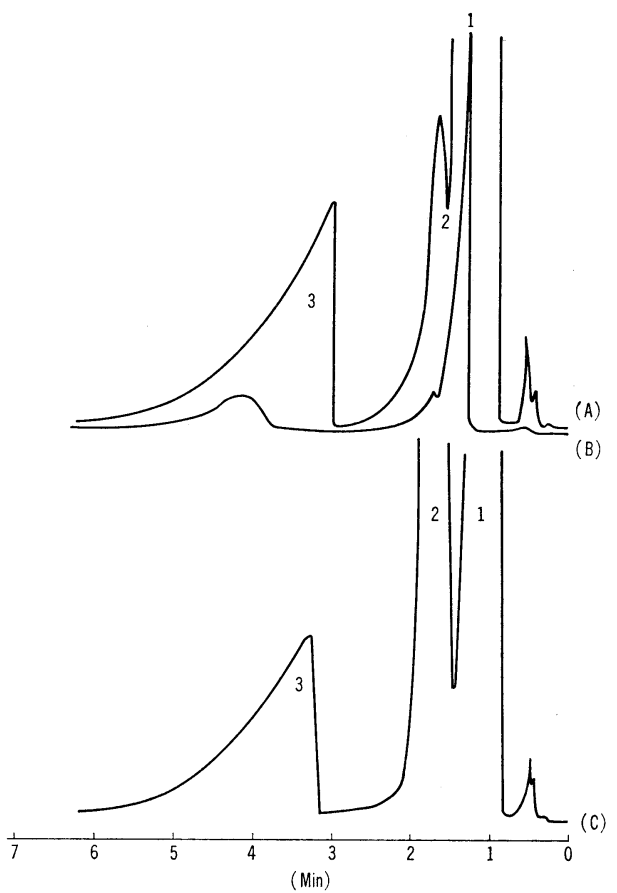

Fig. 4. Gas chromatogram of solvent liquid.

Porapak P column of $150 \mathrm{~cm}$ was used at $110^{\circ} \mathrm{C}$ and thermal conductivity detector at $190^{\circ} \mathrm{C}$, in flow rate of carrier gas $45 \mathrm{ml} / \mathrm{min}$.

(A) Original sample of $10 \mu 1$. $\quad$ (B) Original sample of $1 \mu \mathrm{l}$. (C) Sample liquid of $10 \mu 1$ which made by mixing original solvent and acetic acid in ratio of to 1 by volume.

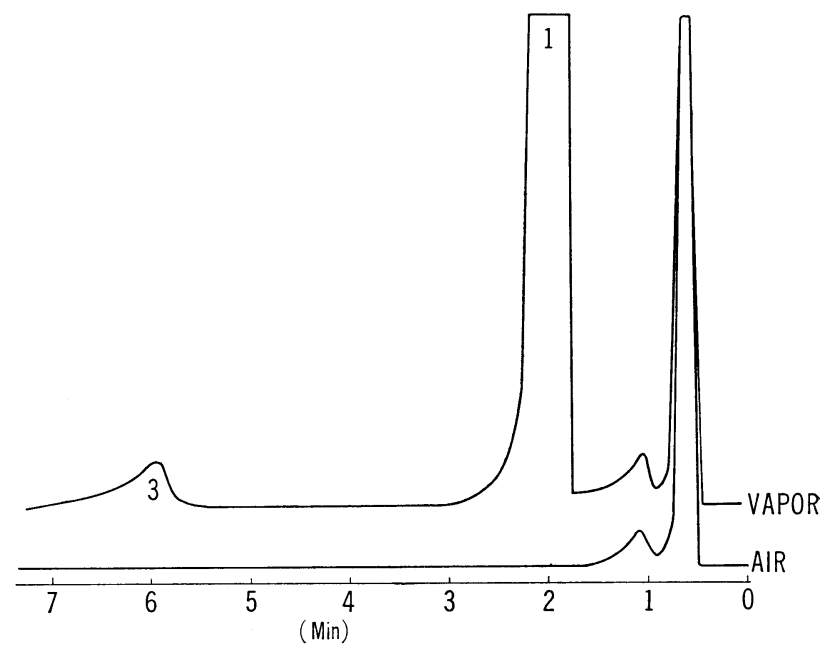

Fig. 5. Gas chromatogram of solvent vapor with gas sampler. Porapak P column of $150 \mathrm{~cm}$ was used at $112^{\circ} \mathrm{C}$ and thermal conductivity detector. Flow rate of carrier gas was $50 \mathrm{ml} / \mathrm{min}$. 
IDENTIFICATIONS OF ORGANIC SOLVENTS

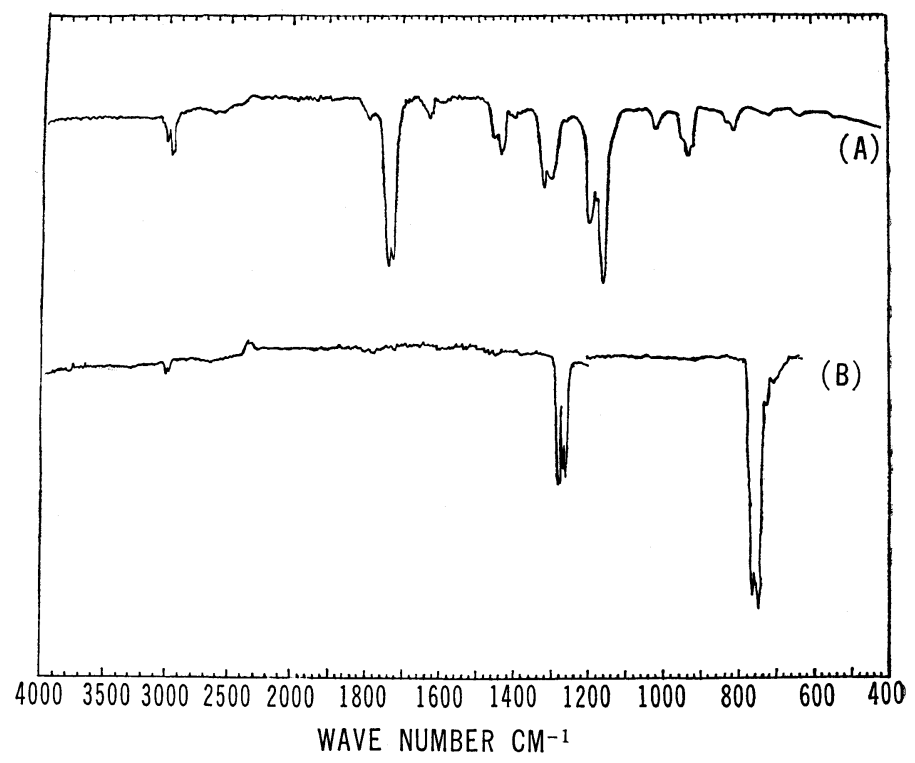

Fig. 6. Infrared spectra of eluates from gas chromatograph for solvent of $10 \mu 1$.

(A) Gas chromatographic third fraction. Spectrum was the same as that of methyl methacrylate vapor. (B) First fraction. Spectrum was the same as that of methylene dichloride vapor.

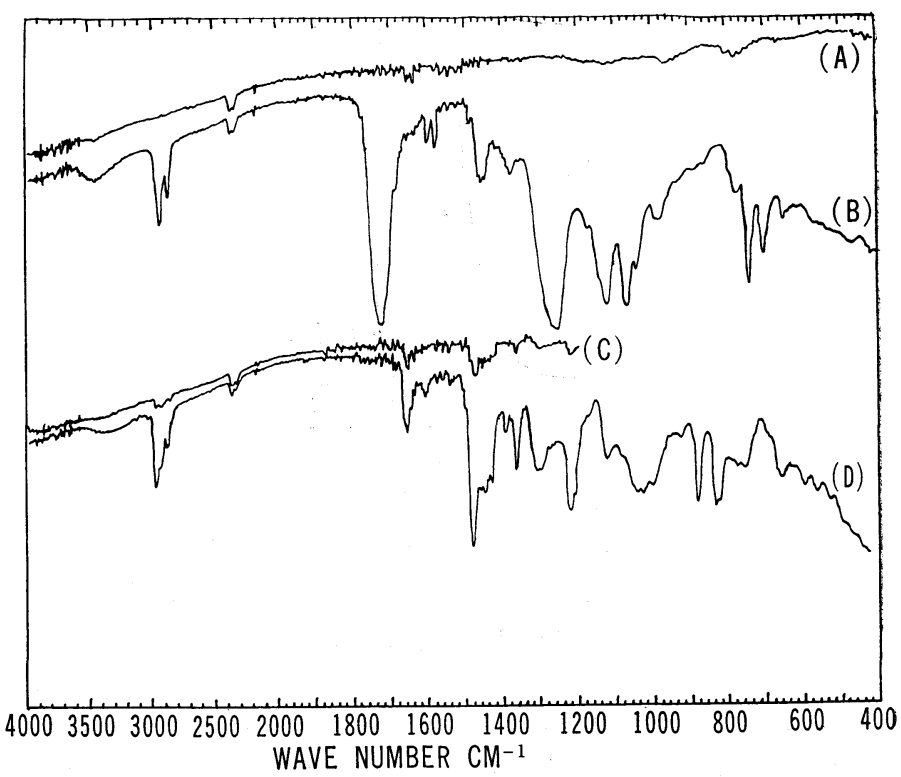

Fig. 7. Infrared spectrum of non volatile components by ATR (A) and (C) are $100 \%$ line of ATR. (B) Non volatile of enamel on teflon sheet heated to evaporate solvents. (D) Non volatile of adhesive on teflon sheet heated to evaporate solvents. 


\section{R. SODA}

aliphatic groups (at 2950 and $2830 \mathrm{~cm}^{-1}$ ) and ester group (at 1750 and $1250 \mathrm{~cm}^{-1}$ ). This substance was considered to be a soya modified alkyd resin. ${ }^{1)}$ Spectrum D in Fig. 7 was obtained by adhesive. Most bands of the sample were explained to be due to aliphatic or aromatic hydrocarbons. At least, existence of functional groups of $\mathrm{OH}, \mathrm{C}=\mathrm{O} \mathrm{COOR}, \mathrm{CHO}$ or other polar groups was excluded from the spectrum. ${ }^{2)}$ The material was considered to be synthetic rubber like polychloroprene from a property of adhesive but spectrum did not show pure polychloroprene. ${ }^{3)}$ In any case this sample was not considered to have strong polar structure. Some of the solvents used for this adhesive were presumed to be rather non polar. Fig. 8 shows the vapor spectrum of adhesive solvent obtained by evapoation standing for large time with the similar apparatus as shown in Fig. 1. Components were estimated to be $\mathrm{n}$-hexane $\left(1460 \mathrm{~cm}^{-1}\right)$, toluene $\left(730 \mathrm{~cm}^{-1}\right)$ and ethyl acetate $(1760$ and $1240 \mathrm{~cm}^{-1}$ ) and others. Gas chromatographic analysis of vapor gave the same result as that obtained infrared spectrum.

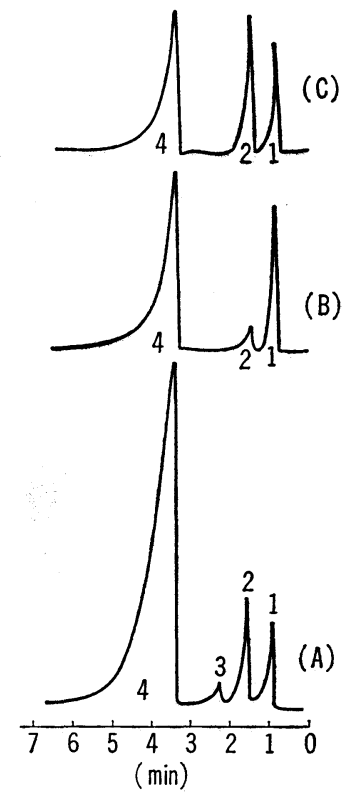

Fig. 8. Infrared spectra of volatile components of adhesive vapor from adhesive by standing for about $30 \mathrm{~min}$ to establish vapor liquid equilibrium.

The results shown in Fig. 9 to Fig. 13 were obtained with organic solvents which did not contain any non volatile substances. Therefore solvent liquids were injected directly into gas chromatograph. From gas chromatogram shown in Fig. 9, presented that sample contained acetone, ethyl acetate, and toluene. The addition of infered sample enhanced the height of that peak and decreased the peak of sample which was not added. Fig. 10 presented that the sample analyzed con- 
IDENTIFICATIONS OF ORGANIC SOLVENTS

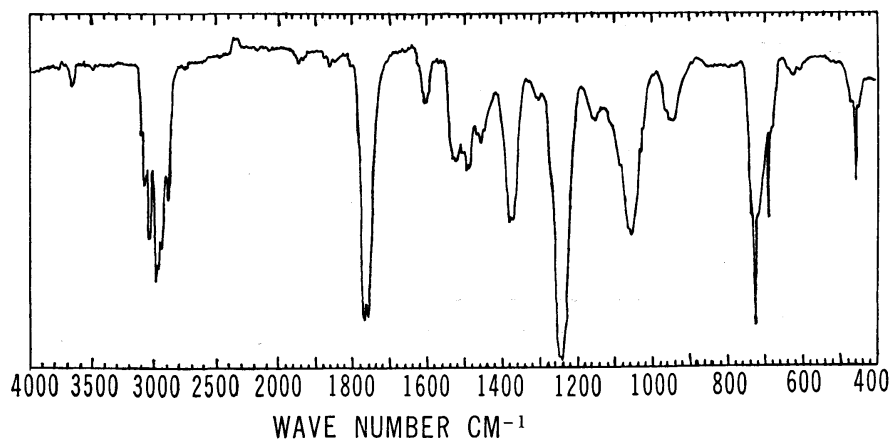

Fig. 9. Gas chromatograms of adhesive solvent.

Porapak $\mathrm{P}$ column of $150 \mathrm{~cm}$ was used at $134^{\circ} \mathrm{C}$ and thermal conductivity detector at $180^{\circ} \mathrm{C}$. Flow rate of carrier gas was $50 \mathrm{ml} / \mathrm{min}$. Sample size of liquid was $1 \mu \mathrm{l}$.

Composition of sample by volume were (A) original liquid, (B) original : acetone : toluene $=1 ; 0.2: 1$, (C) original : acetone : ethyl acetate : toluene=1:0.2:0.4:1.

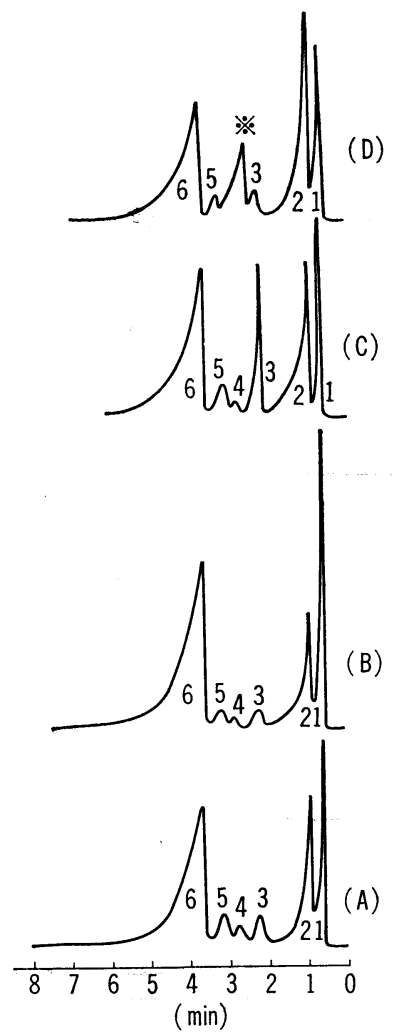

Fig. 10. Gas chromatogram of organic solvent for adhesive.

Porapak $\mathrm{P}$ column of $150 \mathrm{~cm}$ was used at $134^{\circ} \mathrm{C}$ and thermal conductivity detector at $180^{\circ} \mathrm{C}$. Flow rate of carrier gas was $50 \mathrm{ml} / \mathrm{min}$ and sample size of liquid $1 \mu \mathrm{l}$.

Composition of sample by volume were (A) original liquid, (B) original : methanol : toluene $=10: 1: 5$, (C) original : $\mathrm{n}$-heptane $=10: 0.2$, (D) origianl : acetone : benzene $=10:$ $0.5: 1$. 


\section{R. SODA}

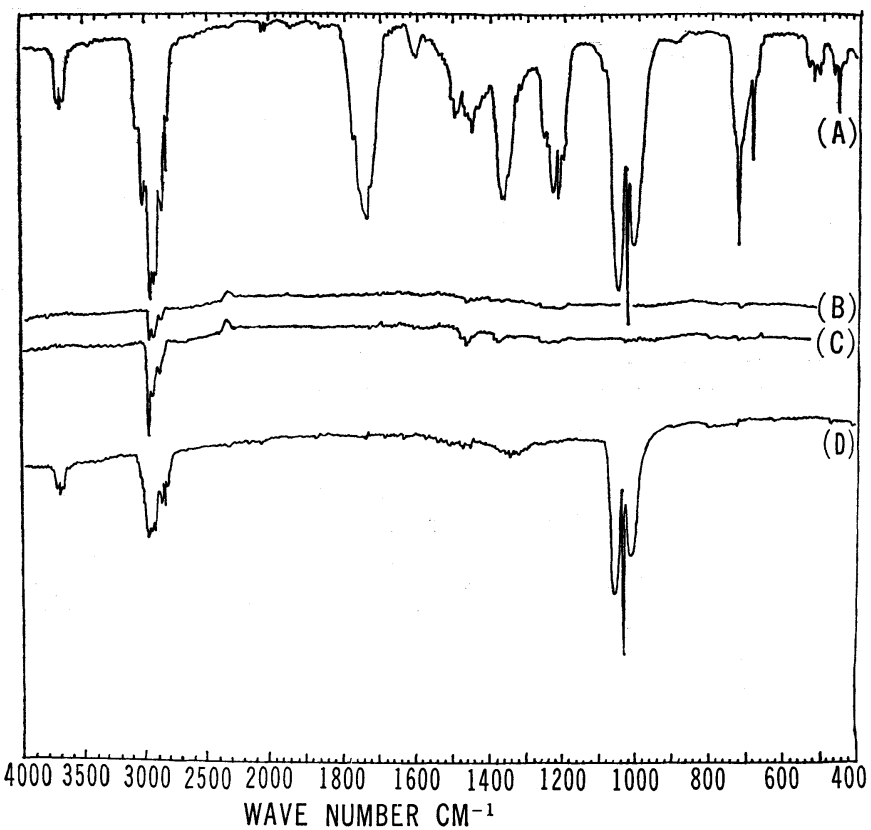

Fig. 11. Infrared spectrum of organic solvent for adhesive.

(A) Vapor in equilibrium with liquid. (B) Forth and fifth peaks of gas chromatographic effluents. (C) Third peak of effluents. (D) First large peak of effluents.

Sample size for gas chromatographic analysis was $10 \mu \mathrm{l}$.

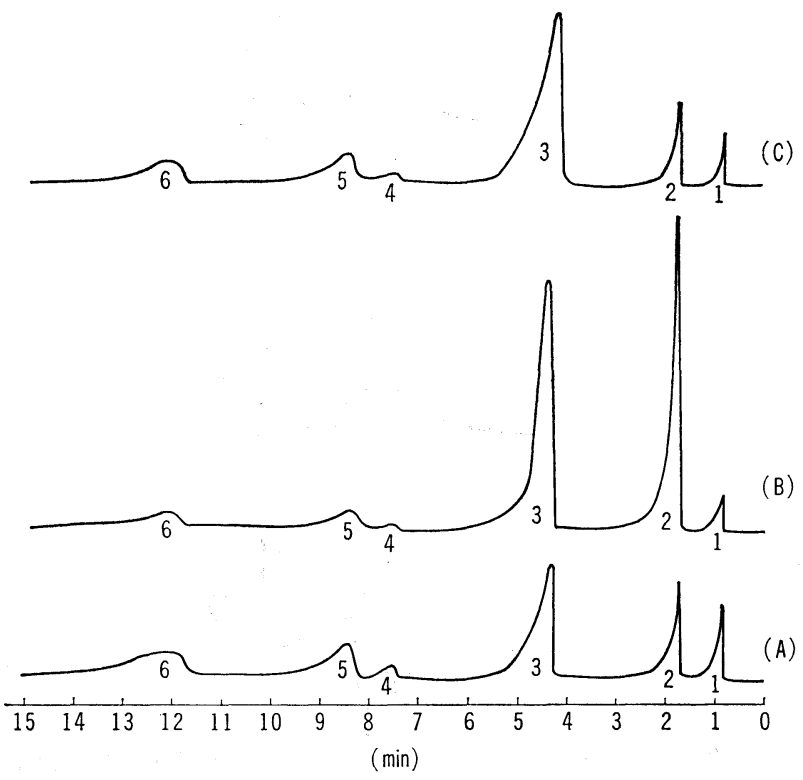

Fig. 12. Gas chromatogram of organic solvent.

Porapak $\mathrm{P}$ column of $150 \mathrm{~cm}$ was used at $154^{\circ} \mathrm{C}$ and thermal conductivity detector at $180^{\circ} \mathrm{C}$. Flow rate of carrier gas was $50 \mathrm{ml} / \mathrm{min}$ and sample size $1 \mu \mathrm{l}$.

Composition of samples by volume were (A) original solvent liquid, (B) original : ethyl acetate : toluene $=1$ : $0.2: 0.5,(\mathrm{C})$ original : n-butyl acetate $=1: 0.2$. 
IDENTIFICATIONS OF ORGANIC SOLVENTS

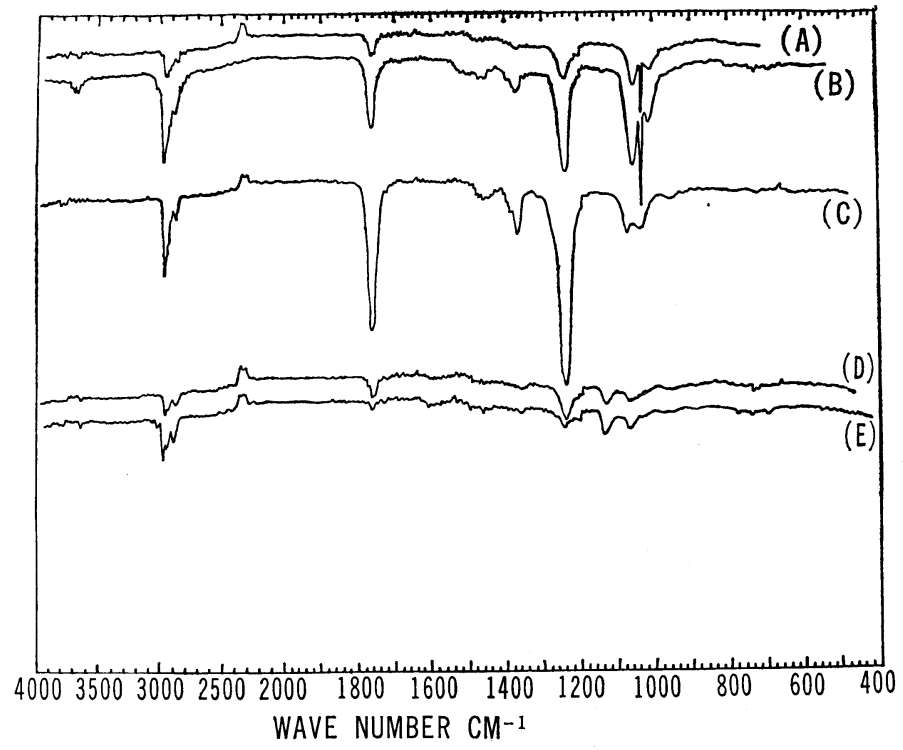

Fig. 13. Infrared spectrum of organic solvent vapor.

(A) Vapor in equilibrium with liquid in gas cell. (B) Gas chromatographic effluents (all peaks). (C) Third peak of gas chromatographic effluents. (D) Forth peak of effluents.

(E) Fifth peak of effluents.

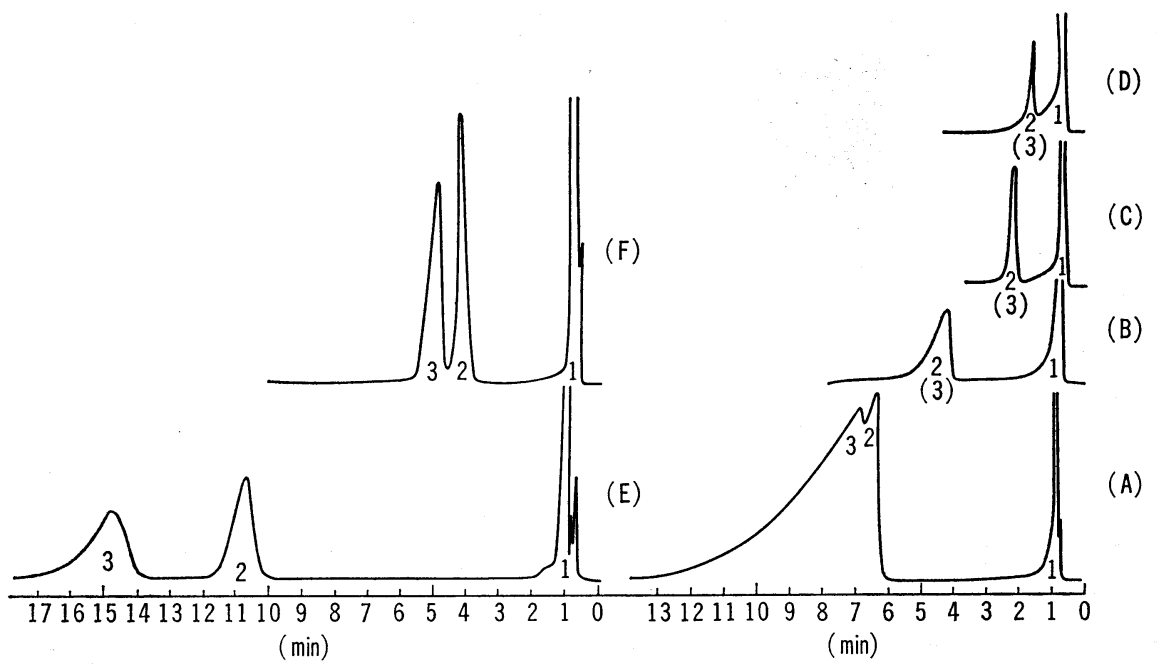

Fig. 14. Gas chromatograms of synthetic solvents.

Thermal conductivity detector was used at $190^{\circ} \mathrm{C}$ Flow rate of carrier gas was $50 \mathrm{ml} / \mathrm{min}$ and sample size $1 \mu 1$ except (A) of $2 \mu \mathrm{l}$. Sample components were methanol, toluene and n-butyl acetate. Mixing ratio by volume and temperature of column were; (A) $1: 1: 1$ and $114^{\circ} \mathrm{C}$, (B) $1: 0.2: 0.2$ and $134^{\circ} \mathrm{C}$, (C) $2: 0.1: 0.1$ and $155^{\circ} \mathrm{C}$, (D) $2: 0.1: 0.1$ and $168^{\circ} \mathrm{C}$, with Porapak $\mathrm{P}$ column of $150 \mathrm{~cm}$. Sample of mixing ratio by volume of $5: 1: 1$ was chromatographed at column temperature of $165^{\circ} \mathrm{C}$ for (E) and $195^{\circ} \mathrm{C}$ for (F) with Porapak Q column of $150 \mathrm{~cm}$. 


\section{R. SODA}

tained methanol, acetone, $\mathrm{n}$-heptane, $\mathrm{n}$-hexane and totuene, did not contain benzene, because bezene addition caused a different peak as marked by asterics on chromatogram D in Fig. 10. Mixture of other authentic samples revealed a increase of peak heights of components added. Furthermore infrared spectra of eluates presented that components were methanol, n-hexane, n-heptane and others as shown in Fig. 11. Spectrum of all volatile components revealed other components than chromatographic fractions analyzed were toluene, ester and ketones.

The example shown in Fig. 12 included some problems in the chromatographic analysis. By chromatogram B in Fig. 12, an addition of toluene in the solvent enhanced third peak and did not change the peak shape itself. Therefore third peak was considered to be toluene. But infrared spectrum of this fraction was not the same as that of toluene vapor but was n-butyl acetate as shown by spectrum $\mathrm{C}$ in Fig. 13. The addition of n-butyl acetate in solvent really increased height of third peak as shown by chromatogram $\mathrm{C}$ in Fig. 12. At last the components of the solvents were determined as methanol, ethyl acetate, n-butyl acetate, aliphatic hydrocarbons such as n-hexane and n-heptane, and other esters. Therefore gas chromatographic analysis with only one condition might, in some cases, mistake identification. With Porapak P column at column temperature of higher than $134^{\circ} \mathrm{C}$, chromatograms did not show the separation of toluene and n-butyl acetate peaks, and at $114^{\circ} \mathrm{C}$ a slight split of peaks was observed as shown in Fig. 14. But with Porapak $\mathrm{Q}$ column n-butyl acetate and toluene were identified separately at any temperature but separation was poorer with higher temperature of column oven.

\section{Discussion}

Toxic organic solvents which contaminate ambient air are all volatile substances. Therefore the analysis of such substances in commercial material is significant prior to practical process of environmental analysis.

Vapors and gases are usually analyzed by gas chromatography.4 8) The determination of concentration or amounts is easier by that instrument than by other methods, but identification of unknown components is difficult frequently with gas chromatography only. Analysis of mixture of gaseous substances is carried out by gas chromatography which separates each components to determine individually the amounts of components. Infrared method is not suitable to identify the mixture of many components because the spectrum becomes very complicated with such a mixture which gives rise to all bands in spectrum. But identification of one component is easily obtainable by infrared spectroscopy which gives full information on the compound. The combination of both methods may be very useful as both analytical methods are supplementary, as indicated in present experimental results. ${ }^{9 \sim 13)}$ Major volatile components in the commercial materials are easily identified and determined semiquantitatively by gas chromatography and infrared spectroscopy. 


\section{IDENTIFICATIONS OF ORGANIC SOLVENTS}

Infrared identification needs standard vapor spectrum of pure solvent and table of key bands (a few strongest bands). The latter is used for estimation of substance in question. A comparison of the spectrum with standard spectrum of infered substance is used to confirm above estimation. Gas chromatographic method needs the table of relative retention time with column and temperature used. Column material and the temperature change the retention time largely. This is one example shown in Fig. 14, in which n-butyl acetate and toluene changes their chromatographic behavior with column materials and column temperatures. The infrared spectroscopic identification of each peak is very useful for gas chromatographic analysis. Recent developement of instrument replaces the role of the infrared spectroscopy by mass spectrometric analysis, because the latter performs. identification very fast. ${ }^{14,15)}$

The infrared analysis with ATR for non volatile component is also practically preferable to analysis of volatile components. The identification of non volatile compounds make the inference of volatile components easy. The properties of non volatile substances are an important key to select kinds of solvents. Therefore from characteristics of functional groups in those substances, molecular weight, chemical constitution and other properties, the solvents used are probably inferable and this process make the identification of solvents easier.

\section{ACKNOWLEDGEMENT}

The author gives his hearty thanks to Mr. Takano in this Institute for his performance of gas chromatographic analysis in present paper.

\section{REFERENCES}

1) Hannah, R.W. and Dwyer, J.L. (1964). Anal. Chem., 36, 2341.

2) Bellamy, L.J. (1954). The Infra-red Spectra of Complex Molecules, Methuen \& Co. Ltd., London.

3) Dinsmore, H.L. and Smith, D.C. (1948). Anal. Chem., 20, 11.

4) Matsumura, Y. and Soda, R. (1960) Bull. Nat. Inst. Ind. Health, No. 4, 44.

5) Novák, J., Vasák, V. and Janák, J. (1965). Anal. Chem., 37, 660

6) Williams, I.H. (1965). Anal. Chem., 37, 1723.

7) White, L.D., Taylor, D.G., Mauer, P.A. and Kupel, R.E. (1970). Am. Ind. Hyg. Assoc. J., 31, 225.

8) Houten, R.V. and Lee G. (1969). Am. Ind. Hyg. Assoc. J., 30, 465

9) Behrendt, S. (1968). J. Gas Chromatog. 6, 226.

10) Ballinger, J., Bartels, T.T. and Taylor, J.H. (1968). J. Gas Chromatog. 6, 295.

11) Littlewood, A.B. (1968). J. Gas Chromatog., 6, 65.

12) Brown, D., Earnshaw, D.G., McDonald, F.R. and Jensen, H.B. (1970). Anal. Chem, 42, 146.

13) Duswalt, J.M. and Mayer, T.J. (1970). Anal. Chem., 42, 1789.

14) Sarfaty, G.A. and Fales, H.M. (1970). Anal. Chem., 42, 288.

15) Schoengold, D.M. and Munson, B. (1970). Anal. Chem. 42, 1811. 